ПРОГНОЗИРОВАНИЕ ТАЗОВЫХ ПЕРИТОНЕАЛЬНЫХ СПАЕК НА ФОНЕ НЕДИФФЕРЕНЦИРОВАННОЙ ДИСПЛАЗИИ СОЕДИНИТЕЛЬНОЙ ТКАНИ У ЖЕНЩИН С ХРОНИЧЕСКОЙ ТАЗОВОЙ БОЛЬЮ

\author{
М. Бен Салха, Н.Б. Репина, М.Н. Дмитриева, А.А. Никифоров, И.А. Усачев \\ ФГБОУ ВО «Рязанский государственный медицинский университет имени академика И.П. Павлова» \\ Министерства здравоохранения Российской Федерации
}

\begin{abstract}
Цель: оптимизировать комплекс диапностических мероприятий в предоперационном периоде у пациенток с недифференцированной дисплазией соединительной ткани на основании клиническо-анамнестических и молекулярногенетических предикторов для повышения эфрфективности профилактики спайкообразования и его осложнений. Материал и методы: исследование проведено на базе ГБУ РО «Областной клинический перинатальный центр», в ходе которого проанализировано 180 пациенток с диагнозом трубно-перитонеальное бесплодие. Пациентки разделены на 2 группы на основании модифицированной балльной шкалы Т.И. Кадуриной. Проведены исследование гено-френотипических предикторов путем анализа выраженности недифференцированной дисплазии соединительной ткани методом профилирования фенотипических маркеров по модифицированной шкале Т.И. Кадуриной; изучение полиморфизма генов VEGF 634 [rs2010963] и IL6-174 [rs1800795] и оценка выраженности спаечного процесса согласно классификационной системе Американского общества фрертильности, генетической предрасположенности к развитию спаечного процесса методом генотипирования ацетилирования и интенсивности боли по визуально-аналоговой шкале. Результаты: клиническими признаками недифференцированной дисплазии соединительной ткани являются варикозное расширение вен нижних конечностей $(p=0,037)$, пролапс митрального клапана $(p=0,044)$, миопия $(p=0,0007)$ и хронический пиелонесррит $(p=0,024)$, а внешними фенотипическими - гиперпигментация кожи над остистыми отростками позвонков $(p<0,0001)$, наличие келоидных рубцов $(p<0,0001)$ и тонкой, легко ранимой кожи $(p<0,0001)$. Диагностика генетической предрасположенности к спаечному процессу методом определения френотипа ацетилирования позволяет предположить наличие спаек в малом тазу у $77,5 \%$ ( $p=0,033)$, а при применении ультразвуковой диагностики - в 66,66 \% $(p<0,0001)$ у обследованных пациенток до операции. Предсказательная ценность УзИ при диагностике СП на основании признаков: «Нечеткий контур» является 49,18\% (Cl=0,57-1,55; OR =0,94; $p=0,158)$, наличие жидкостных образований в малом тазу - 59,01 \% $(\mathrm{Cl}=1,24-3,45 ; \mathrm{OR}=2,07 ; \mathrm{p}<0,0001)$, «Расстояние» - 72,13 \% (Cl = 3,83-11,73; OR = 6,70; $p<0,0001)$ и фриксация яичника в абнормальной локализации - 79,5 \% (Cl = 8,08-28,03; OR = 15,05; $p<0,0001)$. Специфичность ультразвукового исследования при диагностике спаечного процесса в малом тазу на основании косвенных критериев («нечеткий контур», «фиксация», «расстояние» и наличие жидкостных образований в малом тазу, не связанных с яичником) составляет при 3-4-й стадии распространения спаечного процесса - 97,05 \% (100-94,11 \%) а при 1-2-й стадии - 43,48 \% (24-62,96 \%). Признаками высокой вероятности развитии спаечного процесса при ГСГ являются «локуляции» и атипичное расположение маточной трубы. При исследовании хронической тазовой боли в зависимости от стадии спаечного процесса было доказано и достоверно, что чем более продвинутая стадия спаечного процесса, тем более интенсивный характер хронической тазовой боли $(R=0,695 ; p<0,05 ;$ критерий с2 = 67,25; коэффициент взаимной сопряженности К. Пирсона 0,518). Молекулярно-генетическими предикторами недифференцированной дисплазий соединительной ткани являются IL6-174 [rs1800795] генотип C/C $(p=0,039)$ и аллель C $(p=0,035)$ и VEGFA 634 [rs2010963] генотип C/G $(p=0,038)$ и аллель $\mathrm{G}$ $(p=0,047)$. Внедрение разработанного алгоритма прогнозирования риска развития тазовых перитонеальных спаек на фоне недифференцированной дисплазий соединительной ткани способствует сохранению репродуктивной функции. Заключение: на основании комплекса инфрормативных, высокоточных и экономных методов аппаратной и лабораторной диагностики - профилирование фенотипических маркеров по модифицированной шкале Т.И. Кадуриной, фенотипирование ацетилирования и молекулярно-генетическое исследование полиморфизма генов (VEGF 634 [rs2010963] и IL6-174 [rs1800795]) - нами было возможно определить вероятность развития тазовых перитонеальных спаек на фроне недифференцированной дисплазии соединительной ткани
\end{abstract}

Ключевые слова: тазовые перитонеальные спайки, недифференцированная дисплазия соединительной ткани, хроническая тазовая боль, ацетилирование, сосудистый эндотелиальный фрактор роста, интерлейкин 6.

\title{
PREDICTION OF PELVIC PERITONEAL SUPPORTING AGAINST THE BACKGROUND OF UNDIFFERENTIATED CONNECTIVE TISSUE DYSPLASIA IN WOMEN WITH CHRONIC PELVIC PAIN
}

\author{
M. Ben Salha, N.B. Repina, M.N. Dmitrieva, A.A. Nikiforov, I.A. Usachev \\ FSBEI HE «Ryazan state medical University named after academician I.P. Pavlov» \\ of Public Health Ministry of the Russian Federation
}

Purpose: to optimize the complex of diagnostic measures in the preoperative period in patients with undifferentiated connective tissue dysplasia on the basis of clinical-anamnestic and molecular genetic predictors to increase the effectiveness of adhesions prevention and its complications. Material and Methods: The study was conducted on the basis of the Regional Clinical Perinatal Center, in which 180 patients with a diagnosis of tuboperitoneal infertility were analyzed. Patients were divided 
into 2 groups on the basis of a modified point scale T.I. Kadurina. The study of gene phenotypic predictors was carried out by analyzing the severity of undifferentiated connective tissue dysplasia using the modified T.I. Kadurina scale; study of polymorphism of VEGF 634 [rs2010963] and IL6-174 [rs1800795] genes and assessment of adhesion severity according to the classification system of the American Fertility Society, genetic predisposition to adhesions development by the method of genotyping acetylation and pain intensity on a visual-analogue scale. Results: the clinical signs of undifferentiated connective tissue dysplasia are varicose veins of the lower extremities $(p=0,037)$, mitral valve prolapse $(p=0,044)$, myopia $(p=0,0007)$, and chronic pyelonephritis $(p=0,024)$ and external phenotypic - hyperpigmentation skin above the spinous processes of vertebrae $(p<0,0001)$, the presence of keloid scars $(p<0,0001)$ and thin, easily vulnerable skin $(p<0,0001)$. Diagnosis of genetic predisposition to adhesions by the method of determining the phenotype of acetylation suggests the presence of adhesions in the small pelvis in $77,5 \%(p=0,033)$, and in the application of ultrasound diagnostics - in $66,66 \%(p<0,0001)$ in the examined patients operations. The predictive value of ultrasound in the diagnosis of SP on the basis of signs: «Fuzzy contour» is $49,18 \%(\mathrm{Cl}=0,57-1,55$; $\mathrm{OR}=0,94 ; p=0,158)$, the presence of liquid formations in the small pelvis is $59,01 \%(\mathrm{Cl}=1,24-3,45 ; \mathrm{OR}=2,07$; $p<0,0001)$, Distance $-72,13 \%(\mathrm{Cl}=3,83-11,73 ; \mathrm{OR}=6,70 ; p<0,0001)$ and fixation of the ovary in abnormal localization $79,5 \%(\mathrm{Cl}=8.08-28.03 ; \mathrm{OR}=15,05 ; p<0,0001)$. The specificity of ultrasound in the diagnosis of adhesions in the pelvis on the basis of indirect criteria («fuzzy contour», «fixation», "distance» and the presence of fluid formations in the pelvis, not related to the egg ik) at 3-4 stages of adhesion process distribution - 97,05 \% (100-94,11\%) and at stages 1-2 - 43,48\% (24-62,96\%). Signs of a high probability of the development of adhesions in the GHA are «locality» and the atypical location of the fallopian tube. In the study of chronic pelvic pain, depending on the stage of adhesions, it has been proven and reliably that the more advanced the adhesions, the more intense the nature of chronic pelvic pain $(R=0,695 ; p<0,05$; criterion $c 2=67,25$; the coefficient of mutual conjugacy of $\mathrm{K}$. Pearson $(0,518)$. Molecular genetic predictors of undifferentiated connective tissue dysplasia are the IL6-174 [rs1800795] C/C genotype $(p=0,039)$ and the $C$ allele $(p=0,035)$ and the VEGFA 634 [rs2010963] C/G genotype $(p=0,038)$ and allele $\mathrm{G}(p=0,047)$. The introduction of the developed algorithm for predicting the risk of developing pelvic peritoneal adhesions against the background of undifferentiated connective tissue dysplasia contributes to the preservation of reproductive function. Conclusion: on the basis of a complex of informative, high-precision and economical methods of instrumental and laboratory diagnostics - profiling phenotypic markers on a modified T.I. Kadurina scale, phenotyping of acetylation and molecular genetic research of gene polymorphism (VEGF 634 [rs2010963] and IL6-174 [rs1800795]) - we were able to determine the likelihood of the development of pelvic peritoneal adhesions against the background of undifferentiated connective tissue dysplasia.

Key words: pelvic peritoneal adhesions, undifferentiated connective tissue dysplasia, chronic pelvic pain, acetylation, vascular endothelial growth factor, interleukin 6 .

Спайки в малом тазу - это образования, которые чаще возникают после оперативных или инвазивных вмешательств в тазу, что может нарушать топику органов и вызывать выраженный болевой синдром. По структуре спайки являются продуктом наслаивания фрибрина и других соединительнотканных элементов [8, 12]. Течение спаечного процесса в малом тазу может быть различной степени выраженности, от бессимптомного до выраженной клинической картины, что требует правильной диагностики и коррекции данного процесса $[1,10,14]$.

Эпидемиология развития спаечных процессов малого таза такова, что более 75 \% оперативных вмешательств рано или поздно осложняются образованием спаек, а это каждая вторая женщина, которая перенесла оперативное вмешательство. Количество спаек после открытого кесаревого сечения вдвое больше, чем после лапароскопических операций $[4,5,11]$. Более 45 \% случаев болевого синдрома в животе и нарушений овариоменструального цикла являются последствием образования спаек в малом тазу. Учитывая распространенность проблемы, необходимо принимать первичные меры профилактики по отношению к спаечному процессу в малом тазу $[9,16,17]$.

Первые признаки проявлений спаечного процесса в малом тазу чаще всего манифестируют болевым синдромом. Это связано с тем, что в малом тазу есть много нервных сплетений и огромное количество нервных окончаний на брюшине малого таза. Поэтому при натяжении брюшины происходит ее раздражение, что проявляется болью и тяжестью в животе. Боли при спайках в малом тазу имеют свои характеристики: боль имеет тупой характер, постоянная, локализуется внизу живота [2]. Они могут усиливаться, в связи с менструациями, что может быть из-за компрессии нервных окончаний при увеличении матки. Такой болевой синдром неинтенсивный и плохо поддается лечению спазмолитиками. Особенностью такой боли является то, что они однотипные и не усиливаются, не имеют прогрессирующий характер. Если характер боли изменился или если изменилась локализация, то стоит задуматься об этом, ведь это может быть признаком развития осложнений [13].

Склонность к формированию спаек, являясь одним из вариантов недифференцированных форм дисплазии соединительной ткани, является генофенотипически обусловленной $[7,15]$.

\section{ЦЕЛЬ РАБОТЫ}

Оптимизировать комплекс диагностических мероприятий в предоперационном периоде у пациенток c недифференцированной дисплазией соединительной ткани (нДСТ) на основании клиническоанамнестических и молекулярно-генетических предикторов для повышения эффеектинности профилактики спайкообразования и его осложнений.

\section{МЕТОДИКА ИССЛЕДОВАНИЯ}

Проведен ретроспективный анализ результатов обследования 180 женщин. При этом, по данным амбулаторного наблюдения и диагностического исследования, имело место сочетание трубноперитонеального бесплодия в анамнезе со спайками различной степени выраженности и хронической тазовой болью (ХТБ).

На основании модифицированной шкалы Т.И. Кадуриной, все пациентки были разделены на две группы. В основную группу вошла 81 женщина с выраженностью баллов нДСТ, равной 10 
и более. В группу сравнения вошли 99 пациенток с интервалом баллов от 0 до 9 включительно. Проведена оценка выраженности нДСТ по модифицированной шкале Т.И. Кадуриной (табл. 1) [6].

Таблица 1

Модифицированная шкала Т.И. Кадуриной

\begin{tabular}{|c|c|}
\hline Признаки & Баллы \\
\hline Отслойка сетчатки & 6 \\
\hline ХОБЛ & 5 \\
\hline $\begin{array}{l}\text { Гиперпигментация кожи над остистыми } \\
\text { отростками позвонков }\end{array}$ & 4 \\
\hline $\begin{array}{l}\text { Кожа гиперэластичная } \\
\text { - легкая степень } \\
\text { - умеренная степень } \\
\text { - выраженная степень }\end{array}$ & $\begin{array}{l}4 \\
6 \\
8\end{array}$ \\
\hline Мягкие ушные раковины & 3 \\
\hline Плоскостопие & 3 \\
\hline $\begin{array}{l}\text { Сколиоз } \\
\text { - I степени } \\
\text { - II степени } \\
\text { - III степени }\end{array}$ & $\begin{array}{l}3 \\
4 \\
6\end{array}$ \\
\hline Тонкая, легко ранимая кожа & 3 \\
\hline Ювенильный остеохондроз & 3 \\
\hline $\begin{array}{l}\text { Варикозное расширение вен нижних } \\
\text { конечностей } \\
\text { - легкой степени } \\
\text { - средней степени } \\
\text { - тяжелой степени }\end{array}$ & $\begin{array}{l}2 \\
3 \\
4\end{array}$ \\
\hline Вегетативная дистония & 2 \\
\hline Дискинезия желчевыводящих путей & 2 \\
\hline Кариес зубов & 2 \\
\hline $\begin{array}{c}\text { Келоидные рубцы } \\
\text { - единичные } \\
\text { - множественные }\end{array}$ & $\begin{array}{l}2 \\
3\end{array}$ \\
\hline Ломкие, тонкие волосы & 2 \\
\hline Ломкие, мягкие ногти & 2 \\
\hline $\begin{array}{l}\text { Миопия } \\
\text { - легкая } \\
\text { - средняя } \\
\text { - тяжелая }\end{array}$ & $\begin{array}{l}2 \\
3 \\
6\end{array}$ \\
\hline Нарушение прикуса & 2 \\
\hline $\begin{array}{l}\text { Хронический гастродуоденит в сочетании } \\
\text { с рефрлюксной болезнью } \\
\text { - I степени тяжести } \\
\text { - II степени тяжести } \\
\text { - III степени тяжести }\end{array}$ & $\begin{array}{l}2 \\
4 \\
6\end{array}$ \\
\hline Астигматизм & 1 \\
\hline $\begin{array}{l}\text { Пролапс митрального клапана } \\
\text { - без регургитации / с регургитацией I } \\
\text { степени } \\
\text { - с регургитацией II степени } \\
\text { - с регургитацией III степени } \\
\text { - с регургитацией нескольких клапанов }\end{array}$ & $\begin{array}{l}1 \\
2 \\
3 \\
4\end{array}$ \\
\hline Апоплексия яичника & 1 \\
\hline $\begin{array}{l}\text { Неразвивающаяся беременность } \\
\text { в анамнезе }\end{array}$ & 1 \\
\hline Несостоятельность рубца на матке & 1 \\
\hline Преждевременные роды в анамнезе & 1 \\
\hline Эктопия шейки матки & 1 \\
\hline
\end{tabular}

В ходе предоперационной подготовки пациенткам обеих групп проводилось УЗИ брюшной полости на предмет выявления спаечного процесса (СП) в малом тазу, критериями которого являлись [3]:
- наличие нечеткого контура яичника более чем на протяжении 3/4 яичника, а также гиперэхогенные точечные включения («нечеткий контур»);

- отсутствие движения яичников при увеличении давления датчиком, расположение яичника рядом с маткой, не изменяющееся при пальпации («фиксация»);

- увеличение обычного расстояния между яичником и датчиком, которое не изменяется при пальпации передней брюшной стенки и попытке его сократить («расстояние»);

- наличие жидкостных образований в малом тазу («жидкостные образования»), не связанных с яичником (гидросальпинкс, серозоцеле).

Проходимость маточных труб определилась методом гистеросальпингографии (ГСГ). При наличии частично проходимых маточных труб, ГСГ позволяет предположить наличие перитубарных спаек. Критериями диагностики перитубарных спаек были [3]:

- атипичное расположение трубы;

- выраженная «извитость» маточной трубы конвуляция;

- двойной контур;

- отсутствие растекания контрастного препарата при выходе из маточной трубы с формированием локусов его скопления в области дистального отдела с четкими контурами - локуляция.

Выраженность спаечного процесса в малом тазу оценивалась согласно общепринятой классификации. В классификационной системе Американского общества репродукции (AFS, 1988) предусмотрена прогностическая классификация аднексальных спаек, основанная на их лапароскопической оценке, рассчитанной по сумме баллов (табл. 2).

Таблица 2

Классификация аднексальных спаек Американского общества фертильности (1988)

\begin{tabular}{|c|c|c|c|c|c|}
\hline \multicolumn{2}{|c|}{ Орган } & \multirow{2}{*}{$\begin{array}{l}\text { Спайки } \\
\text { пленча- } \\
\text { тые }\end{array}$} & \multirow{2}{*}{$\begin{array}{c}\begin{array}{c}<1 / 3 \text { при- } \\
\text { крыто }\end{array} \\
1\end{array}$} & \multirow{2}{*}{$\begin{array}{c}1 / 3- \\
2 / 3 \\
\text { при- } \\
\text { крыто } \\
2\end{array}$} & \multirow{2}{*}{\begin{tabular}{|c|}
$\begin{array}{c}>2 / 3 \\
\text { при- } \\
\text { крыто }\end{array}$ \\
4
\end{tabular}} \\
\hline Яичники & $\begin{array}{l}\text { пра- } \\
\text { вый }\end{array}$ & & & & \\
\hline & & плотные & 4 & 8 & 16 \\
\hline & левый & $\begin{array}{l}\text { пленча- } \\
\text { тые }\end{array}$ & 1 & 2 & 4 \\
\hline & & плотные & 4 & 8 & 16 \\
\hline \multirow[t]{4}{*}{$\begin{array}{l}\text { Маточные } \\
\text { трубы }\end{array}$} & \multirow[t]{2}{*}{$\begin{array}{l}\text { пра- } \\
\text { вая }\end{array}$} & $\begin{array}{l}\text { пленча- } \\
\text { тые }\end{array}$ & 1 & 2 & 4 \\
\hline & & плотные & 4 & 8 & 16 \\
\hline & \multirow[t]{2}{*}{ левая } & $\begin{array}{l}\text { пленча- } \\
\text { тые }\end{array}$ & 1 & 2 & 4 \\
\hline & & плотные & 4 & 8 & 16 \\
\hline
\end{tabular}

До операции все пациентки, участвующие в исследовании, были подвергнуты специальному клинико-лабораторному методу исследования конституциональной склонности к спайкообразованию. Для определении типа ацетилирования проводится фотоколориметрическая оценка концентрации окрашенного продукта, образующегося при реакции свободного сульфадимезина с нитритом натрия и N-кислотой. 
Для измерения интенсивности боли нами была использована визуально-аналоговая шкала (ВАШ). В последующем проводилось генотипирование пациенток на носительство полиморфизма генов IL6 (174 C/G) [rs1800795] и VEGF (634 G/C) [rs2010963], задействованных в патоморфизме соединительной ткани.

Все количественные характеристики изученных показателей выражались в процентах. Статистический анализ выполнен с использованием следующих пакетов программ: Statistica 13(StatSoft) и SPSS Statistics 20 (IBM).

\section{РЕЗУЛЬТАТЫ ИССЛЕДОВАНИЯ И ИХ ОБСУЖДЕНИЕ}

Для оценки эффрективности модифицированной шкалы Т.И. Кадуриной был произведен ROC-анализ с тазовыми перитонеальными спайками (ТПС). Площадь под кривой составила AUC = 0,747; $p<0,05$ (чувствительность 75 \%; специфичность $84 \%$ ).

Определено пороговое значение cut-off, cootветствующее точке с максимальной чувствительностью и специфичностью. Для ТПС на фоне нДСТ значение cut-off располагалось в интервале между 9,5 и 10,5 баллами. Принимая во внимание вышеуказанное, в качестве порогового приняли значение, равное 10 баллам.

В ходе исследования проанализировано состояние пациентки, а также изучены особенности соматического и гинекологического анамнеза. При исследовании структуры заболеваний сердечнососудистой системы были превалирующим и достоверным в основной группе вегето-сосудистая дистония - 33,33 \% (Cl = 1,17-4,63; $\mathrm{OR}=2,33 ; p=$ 0,014), варикозное расширение вен нижних конечностей (BРВНК) - 27,16 \% (Cl = 1,01-4,50; OR = 2,16; $p=0,037)$ и пролапс митрального клапана (ПМК) $14,81 \%(\mathrm{Cl}=0,99-7,77 ; \mathrm{OR}=2,78 ; p=0,044)$ (рис. 1$)$.

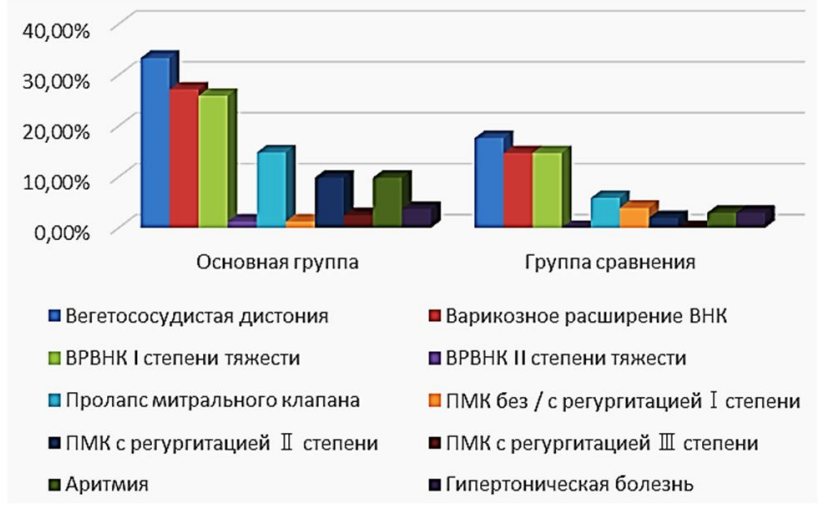

Рис. 1. Распределение заболеваний сердечнососудистой системы в исследуемых группах

При изучении патологии органов зрении было выявлено, что в основной группе практически у каждой второй пациентки нами была отмечена миопия, частота которой составила 49,38 \% (Cl = 1,53-5,31; OR $=2,85 ; p=0,0007)$. Астигматизм наблюдался в основной группе в 2 раза чаще, его частота равна $24,69 \%(\mathrm{Cl}=1,32-6,89 ; \mathrm{OR}=3,02$; $p=0,006)$, а отслойки сетчатки $-7,4 \%(\mathrm{Cl}=0,95-$ 68,$54 ; \mathrm{OR}=8,08 ; p=0,024$ ) (рис. 2).

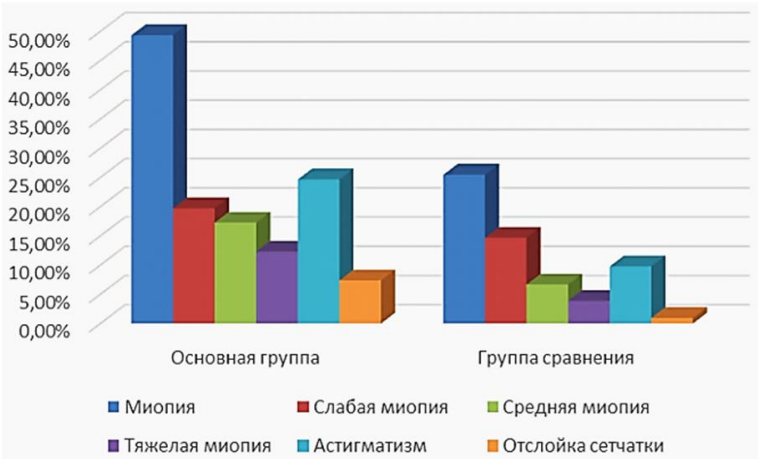

Рис. 2. Распределение патологии органов зрении в исследуемых группах

Исследование структуры заболеваний мочевыделительной системы показало, что хронический пиелонефрит был диагностирован у 23,45 \% пациенток основной группы $(\mathrm{Cl}=0,95-68,54 ; \mathrm{OR}=$ $8,08 ; p=0,024)$, хронический цистит $-20,98 \%(\mathrm{Cl}=$ 0,62-17,42; OR = 3,29; $p=0,14)$, нефроптоз - 8,64 \% $(\mathrm{Cl}=0,23-28,75 ; \mathrm{OR}=2,56 ; p=0,43)$ и мочекаменная болезнь - 7,4 \% ( $\mathrm{Cl}=1,04-5,08 ; \mathrm{OR}=2,30 ; p=0,36)$ (рис. 3).

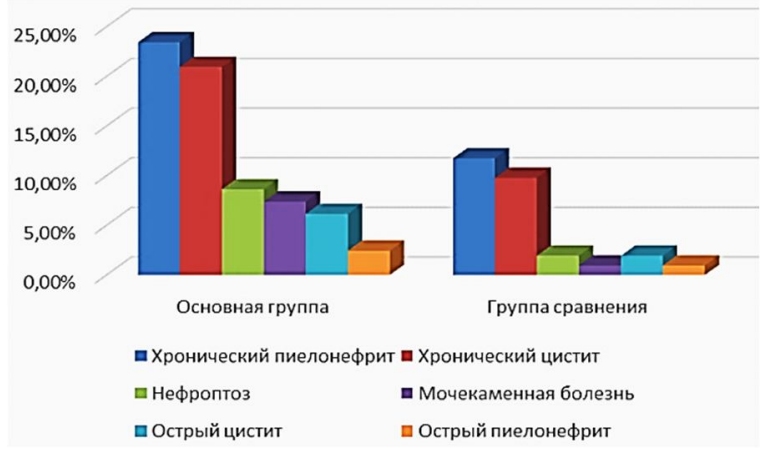

Рис. 3. Распределение заболеваний мочевыделительной системы в исследуемых группах

Среди заболеваний желудочно-кишечного тракта достоверны и чаще встречаются в основной группе дискинезия желчевыводящих путей (ДЖК) $34,8 \%(\mathrm{Cl}=1,05-3,96 ; \mathrm{OR}=2,04 ; p=0,034)$, хронический гастрит - 30,86 \% (Cl = 1,04-4,16; OR = 2,08; $p=0,036)$, хронический гастродуоденит (ХГДД) $13,58 \%(\mathrm{Cl}=1,01-9,17 ; \mathrm{OR}=3,05 ; p=0,039)$ и хронический холецистит - 9,87 \% (CI = 0,93-14,12; OR = $3,62 ; p=0,050)$ (рис. 4).

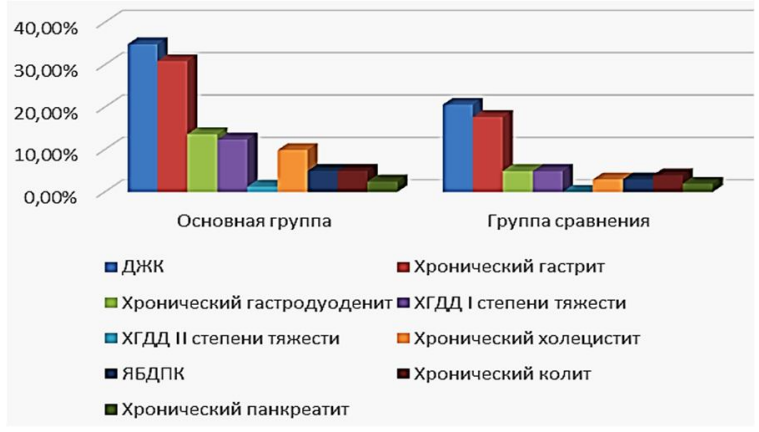

Рис. 4. Распределение заболеваний желудочнокишечного тракта в исследуемых группах 
При исследовании внешних фенотипических признаков недифференцированной дисплазии соединительной ткани в основной группе превалировали наличие мягких ушных раковин - 50,46 \% (Cl = 3,96-15,01; OR = 7,71; $p<0,0001)$, плоскостопие - 48,59\% $\%(\mathrm{Cl}=4,23-16,56 ; \mathrm{OR}=8,37 ; p<0,0001)$, сколиоз - 46,72 \% (Cl = 2,91-10,56; OR = 5,54; $p<0,0001)$, наличие тонкой, легко ранимой кожи $44,85 \%(\mathrm{Cl}=14,01-164,41 ; \mathrm{OR}=48 ; p<0,0001)$, нарушение прикуса - 37,38 \% (Cl = 3,48-15,39; $\mathrm{OR}=7,32 ; p<0,0001)$, наличие келоидных рубцов $36,44 \%(\mathrm{Cl}=10,72-201,13 ; \mathrm{OR}=46,43 ; p<0,0001)$, наличие ломких, мягких ногтей - 32,71\% (Cl = 1,25$4,39 ; \mathrm{OR}=2,34 ; p=0,007)$, наличие гиперэластичной кожи - 28,97 \% (Cl = 2,38-11,07; OR = 5,13; $p<0,0001)$, наличие ломких, тонких волос $-26,16 \%$ $(\mathrm{Cl}=2,01-9,49 ; \mathrm{OR}=4,37 ; p<0,0001)$, гиперпигментация кожи над остистыми отростками позвонков $20,56 \%(\mathrm{Cl}=4,2-82,12 ; \mathrm{OR}=4,23 ; p<0,0001)$ и ювенильный остеохондроз - 7,4 \% (Cl = 1,08-15,80; $\mathrm{OR}=4,13 ; p=0,026$ ) (рис. 5).

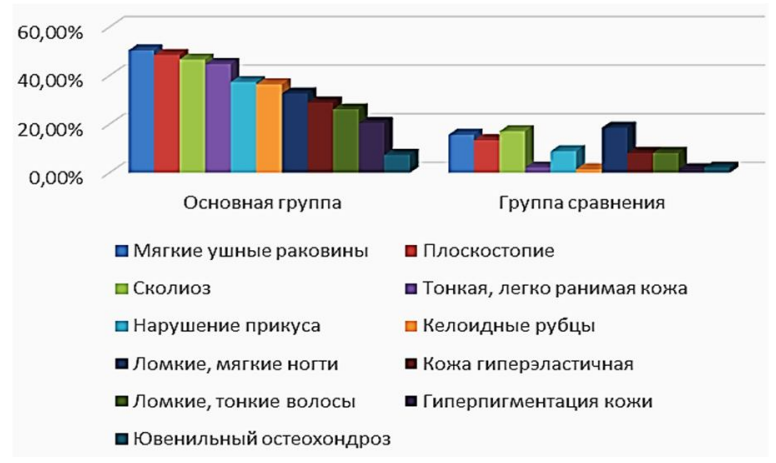

Рис. 5. Распределение внешних фенотипических признаков в исследуемых группах

При анализе структуры акушерско-гинекологических заболеваний было показано, что в основной группе преобладали эктопия шейки матки - 50,46 \% (Cl = 1,75-5,95; OR = 3,23; $p=0,0001)$; преждевременные роды в анамнезе - 20,56 \% (Cl = 1,29-6,09; $\mathrm{OR}=2,8 ; p=0,007) ;$ неразвивающаяся беременность в анамнезе $-14,01 \%(\mathrm{Cl}=1,07-6,66$; $\mathrm{OR}=2,67$; $p=0,03)$; несостоятельность рубца на матке $13,08 \%(p<0,0001)$ и апоплексия яичника $-8,41 \%$ $(\mathrm{Cl}=1,30-29,52 ; \mathrm{OR}=6,19 ; p=0,009)$ (рис. 6).

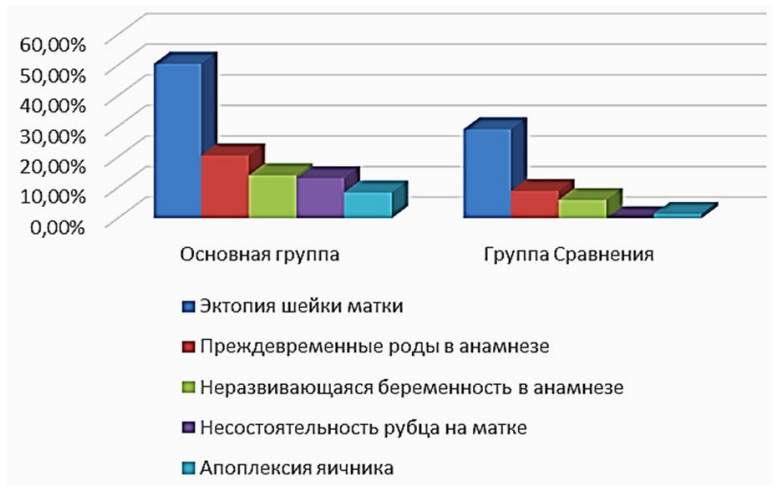

Рис. 6. Распределение акушерско-гинекологических заболеваний в исследуемых группах
Выполнение УЗИ передней брюшной стенки у пациенток с лапаротомными операциями в анамнезе с целью своевременной диагностики висцеропариетальных сращений является обязательным этапом предоперационной диагностики спайкообразования. Так, при УЗИ косвенные признаки СП на дооперационном этапе выявлены нами у 122 (66,66 \%) из 183 женщин и только у 61 (33,33 \%) пациентки СП при УЗИ не был выявлен, но был обнаружен во время лапароскопии.

Предсказательная ценность УЗИ при диагностике СП на основании признаков: «нечеткий контур» $-49,18 \%(\mathrm{Cl}=0,57-1,55 ; \mathrm{OR}=0,94 ; p=0,158)$, наличие жидкостных образований в малом тазу $59,01 \%(\mathrm{Cl}=1,24-3,45$; OR = 2,07; $p<0,0001)$, «pacстояние» - 72,13 \% ( $\mathrm{Cl}=3,83-11,73$; OR = 6,70; $p<0,0001)$ и фиксация яичника в абнормальной локализации - 79,5 \% (Cl = 8,08-28,03; OR = 15,05; $p<0,0001)$ (табл. 3).

Таблица 3

\section{Предсказательная ценность УЗИ} при диагностике СП, абс. (\%)

\begin{tabular}{|c|c|c|c|c|c|}
\hline \multirow{3}{*}{$\begin{array}{c}\text { Группы } \\
\text { исследования } \\
\text { Предсказа- } \\
\text { тельная } \\
\text { ценность } \\
\end{array}$} & \multirow{2}{*}{\multicolumn{3}{|c|}{$\begin{array}{c}\text { Пациентки с 1-2-й } \\
\text { стадией СП } \\
n=46 \\
\end{array}$}} & \multirow{2}{*}{\multicolumn{2}{|c|}{$\begin{array}{c}\text { Пациентки с 3-4-й } \\
\text { стадией СП } \\
n=76\end{array}$}} \\
\hline & & & & & \\
\hline & $\begin{array}{r}\text { "+ } \\
\text { резул }\end{array}$ & & $\begin{array}{c}\text { «-» } \\
\text { результат }\end{array}$ & $\begin{array}{c}\text { «+» } \\
\text { результат }\end{array}$ & $\begin{array}{c}\text { «-» } \\
\text { результат }\end{array}$ \\
\hline \multicolumn{6}{|c|}{ Признаки } \\
\hline $\begin{array}{l}\text { «Расстоя- } \\
\text { ние» }\end{array}$ & \multicolumn{2}{|c|}{$\begin{array}{c}28 \\
(60,86)\end{array}$} & $\begin{array}{c}35 \\
(76,08)\end{array}$ & $\begin{array}{c}60 \\
(78,94)\end{array}$ & $\begin{array}{c}50 \\
(61,72)\end{array}$ \\
\hline $\begin{array}{l}\text { «Нечеткий } \\
\text { контур» }\end{array}$ & \multicolumn{2}{|c|}{$19(41,3)$} & $23(50)$ & $\begin{array}{c}41 \\
(53,94)\end{array}$ & $\begin{array}{c}44 \\
(57,89)\end{array}$ \\
\hline $\begin{array}{l}\text { Фиксация } \\
\text { яичника } \\
\text { в абнормаль- } \\
\text { ной локали- } \\
\text { зации }\end{array}$ & \multicolumn{2}{|c|}{$\begin{array}{c}33 \\
(71,73)\end{array}$} & $\begin{array}{c}36 \\
(78,26)\end{array}$ & $\begin{array}{c}64 \\
(84,21)\end{array}$ & $\begin{array}{c}58 \\
(76,31)\end{array}$ \\
\hline $\begin{array}{l}\text { Наличие } \\
\text { жидкостных } \\
\text { образований } \\
\text { в малом тазу }\end{array}$ & \multicolumn{2}{|c|}{0} & 0 & $\begin{array}{c}72 \\
(94,73)\end{array}$ & 0 \\
\hline \multicolumn{6}{|c|}{ Итого } \\
\hline \multirow{2}{*}{\multicolumn{2}{|c|}{$\begin{array}{c}\text { Пациентки } \\
\text { Предсказательная } \\
\text { ценность } \\
\end{array}$}} & \multicolumn{3}{|c|}{$n=122$} & \multirow[b]{2}{*}{$p$} \\
\hline & & $\begin{array}{r}\text { Поло } \\
\text { ре }\end{array}$ & $\begin{array}{l}\text { жительный } \\
\text { зультат }\end{array}$ & $\begin{array}{c}\text { Отрицатель- } \\
\text { ный результат }\end{array}$ & \\
\hline \multicolumn{6}{|c|}{ Признаки } \\
\hline \multicolumn{2}{|l|}{ «Расстояние» } & \multicolumn{2}{|c|}{$88(72,13)$} & $34(27,86)$ & $\begin{array}{c}p< \\
0,0001\end{array}$ \\
\hline \multicolumn{2}{|c|}{ «Нечеткий контур» } & \multicolumn{2}{|c|}{$60(49,18)$} & $62(50,81)$ & 0,158 \\
\hline \multicolumn{2}{|c|}{$\begin{array}{l}\text { Фиксация яичника } \\
\text { в абнормальной } \\
\text { локализации }\end{array}$} & \multicolumn{2}{|c|}{$97(79,50)$} & $25(20,49)$ & $\begin{array}{c}p< \\
0,0001\end{array}$ \\
\hline \multicolumn{2}{|c|}{$\begin{array}{l}\text { Наличие жидкост- } \\
\text { ных образований } \\
\text { в малом тазу }\end{array}$} & \multicolumn{2}{|c|}{$72(59,01)$} & $50(40,98)$ & $\begin{array}{c}p< \\
0,0001\end{array}$ \\
\hline
\end{tabular}

Специфичность УЗИ при диагностике СП в малом тазу на основании косвенных критериев («нечеткий контур», «фиксация», «расстояние» и наличие жидкостных образований в малом тазу, не связанных с яичником) составляет при 3-4-й стадии распространения СП - 97,05 \% (100-94,11\%), а при 1-2-й стадии - 43,48 \% (24-62,96 \%) (рис. 7). 


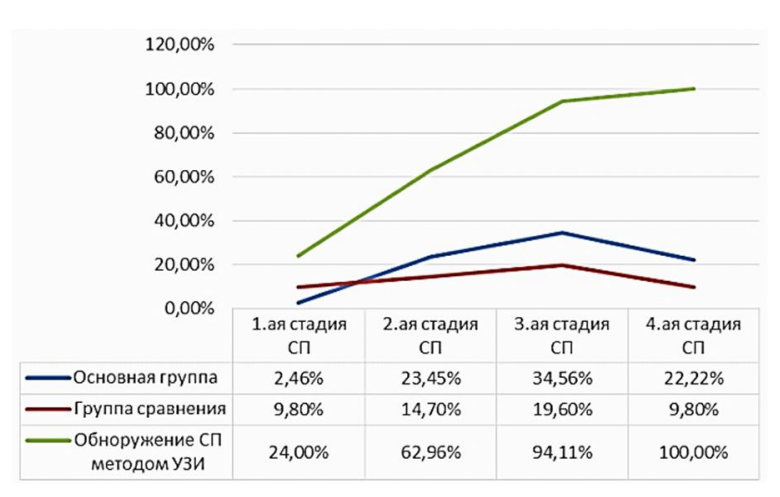

Рис. 7. Обнаружение СП методом УЗИ диагностики

Оценка проходимости маточных труб является важным этапом обследования больных, влияющим на выбор тактики ведения, оценки показаний к оперативному лечению и выбор органо-уносящей/ сохраняющей тактики. Признаками высокой вероятности развития перитубарных спаек являются «локуляции» - 70,49 \% и атипичное расположение маточной трубы - 68,30 \% (табл. 4).

Таблица 4

Исследование наличия спаек перитубарным методом ГСГ, \%

\begin{tabular}{|l|c|c|c|}
\hline \multicolumn{1}{|c|}{ Признаки } & $\begin{array}{c}\text { «+» } \\
\text { результат }\end{array}$ & Чувствительность & Специфичность \\
\hline Локуляция & 70,49 & 91,5 & 79,7 \\
\hline $\begin{array}{l}\text { Атипичное } \\
\text { расположе- } \\
\text { ние трубы }\end{array}$ & 68,30 & 88,7 & 80,1 \\
\hline Конвуляция & 65,57 & 85,2 & 56,3 \\
\hline $\begin{array}{l}\text { Двойной } \\
\text { контур }\end{array}$ & 54,09 & 70,29 & 60,7 \\
\hline
\end{tabular}

Во время проведения лапароскопических вмешательств была оценена степень распространения СП по классификационной системе Американского общества репродукции (AFS, 1988) (табл. 5).

Таблица 5

Стадии распространения спаечного процесса в малом тазу в зависимости от лапароскопической картины, абс. (\%)

\begin{tabular}{|l|c|c|c|c|}
\hline \multirow{2}{*}{ Группы } & \multicolumn{4}{|c|}{ Стадии спаечного процесса } \\
\cline { 2 - 5 } & I & II & III & IV \\
\hline Основная & $4(4,93)$ & $29(35,80)$ & $30(37,03)$ & $18(22,22)$ \\
\hline Сравнения & $46(45,09)$ & $25(24,50)$ & $21(20,58)$ & $10(9,80)$ \\
\hline$P$ & $<0,0001$ & 0,097 & 0,013 & 0,02 \\
\hline
\end{tabular}

В дальнейшем пациенткам определен фенотип ацетилирования. Фенотипирование ацетилирования методом определения уровня активности $\mathrm{N}$-ацетилтрансферазы позволило нам выявить группу риска с генетической предрасположенностью к образованию спаек (табл. 6).

Таблица 6

Тип ацетилирования в исследуемых группах

\begin{tabular}{|l|c|c|}
\hline \multirow{2}{*}{ Группы } & \multicolumn{2}{|c|}{ Тип ацетилирования } \\
\cline { 2 - 3 } & быстрый & медленный \\
\hline Основная & $31(77,5)$ & $9(22,5)$ \\
\hline Сравнения & $18(45)$ & $22(55)$ \\
\hline
\end{tabular}

При анализе полиморфизма IL6 было выявлено, что в основной группе достоверно и чаще встречался генотип $\mathrm{C} / \mathrm{C}-43,33 \%(p=0,044 ; \mathrm{Cl}=1,01-$ $7,25 ; \mathrm{OR}=2,71)$ и аллель $\mathrm{C}-63,33 \%(p=0,043$; $\mathrm{Cl}=1,02-6,59 ; \mathrm{OR}=2,59)$. При изучении полиморфизма VEGFA 634 достоверные различия не имели место, так как частота встречаемости аллеля $\mathrm{G}$ составила $80 \%(\mathrm{Cl}=0,55-4,91 ; \mathrm{OR}=1,65)$, а генотипа $\mathrm{G} / \mathrm{C}-56,66 \%(\mathrm{Cl}=0,78-4,91 ; \mathrm{OR}=1,96)$ (табл. 7).

Таблица 7

Статистические показатели распределения генотипов и аллелей гена IL6-174 [rs1800795] и VEGFA 634 [rs2010963]

\begin{tabular}{|c|l|c|c|c|}
\hline \multicolumn{2}{|c|}{$\begin{array}{c}\text { Распределение генотипов } \\
\text { и аллелей }\end{array}$} & $\mathrm{OR}$ & $\mathrm{Cl}$ & $p$ \\
\hline \multirow{4}{*}{ IL6 -174 } & $\mathrm{G} / \mathrm{G}$ & 0,54 & $0,25-1,19$ & 0,12 \\
\cline { 2 - 5 } & $\mathrm{C} / \mathrm{G}$ & 0,80 & $0,45-1,44$ & 0,45 \\
\cline { 2 - 5 } & $\mathrm{C} / \mathrm{C}$ & 1,91 & $1,03-3,55$ & 0,039 \\
\cline { 2 - 4 } & Аллель C & 1,89 & $1,04-3,42$ & 0,035 \\
\cline { 2 - 4 } & Аллель G & 0,53 & $0,29-0,96$ & \\
\hline VEGFA 634 & $\mathrm{G} / \mathrm{G}$ & 0,54 & $0,30-0,97$ & 0,038 \\
\cline { 2 - 4 } & $\mathrm{C} / \mathrm{G}$ & 1,86 & $1,03-3,36$ & 0,038 \\
\cline { 2 - 4 } & С/C & - & - & - \\
\cline { 2 - 4 } & Аллель C & 0,51 & $0,26-1,00$ & 0,047 \\
\cline { 2 - 4 } & Аллель G & 1,97 & $1,00-3,86$ & \\
\hline
\end{tabular}

При исследовании пациенток на хроническую тазовую боль (ХТБ) выявлено, что ни у одной пациентки она не превышала 3 баллов по шкале ВАШ. Согласно полученным данным, у пациенток с 3-4-й стадией СП отмечали большую степень выраженности 3 балла по шкале ВАШ - 56,96 \%, а по интенсивности 1 балл по шкале ВАШ, практически в 6 раз превышал у пациенток с 1-2-й стадией СП - 64,42 \% (рис. 8).

При проведении корреляционного анализа выявлена достоверная прямая зависимость между интенсивностью характера ХТБ и стадией спаечного процесса ( $r=0,695 ; p<0,05$; критерий с2 = 67,25; коэффициент взаимной сопряженности К. Пирсона 0,518).

При исследовании ХТБ в зависимости от стадии СП было доказано и достоверно, что чем более продвинутая стадия СП, тем более интенсивный характер ХТБ.

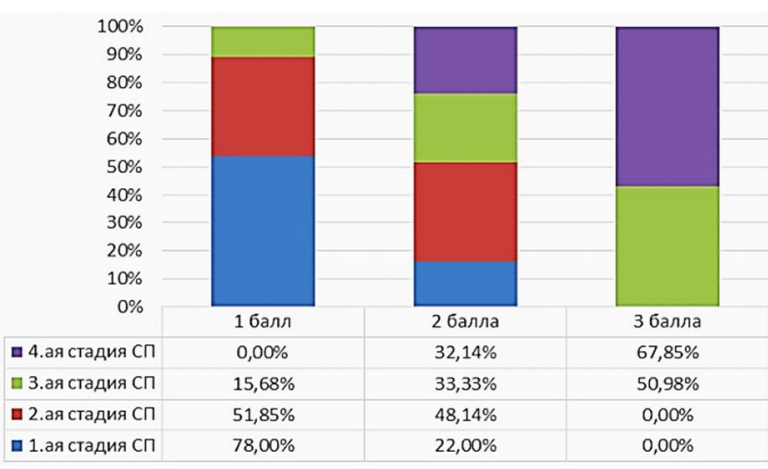

Рис. 8. Оценка интенсивности боли по шкале ВАШ в зависимости от стадии СП

Полученные результаты позволили составить алгоритм ведения пациенток с ТПС на фоне нДСТ 
(см. рис. 4). Исследование гено-френотипических предикторов путем анализа выраженности нДСТ методом профилирования фенотипических маркеров по модифицированной шкале Т.И. Кадуриной и изучение полиморфизма генов VEGF 634 [rs2010963] и IL6-174 [rs1800795], а также определение фенотипа ацетилирования позволяют прогнозировать риск развития ТПС на фоне нДСТ с последующим выбором тактики ведения и оценкой показаний к оперативному лечению (рис. 9).

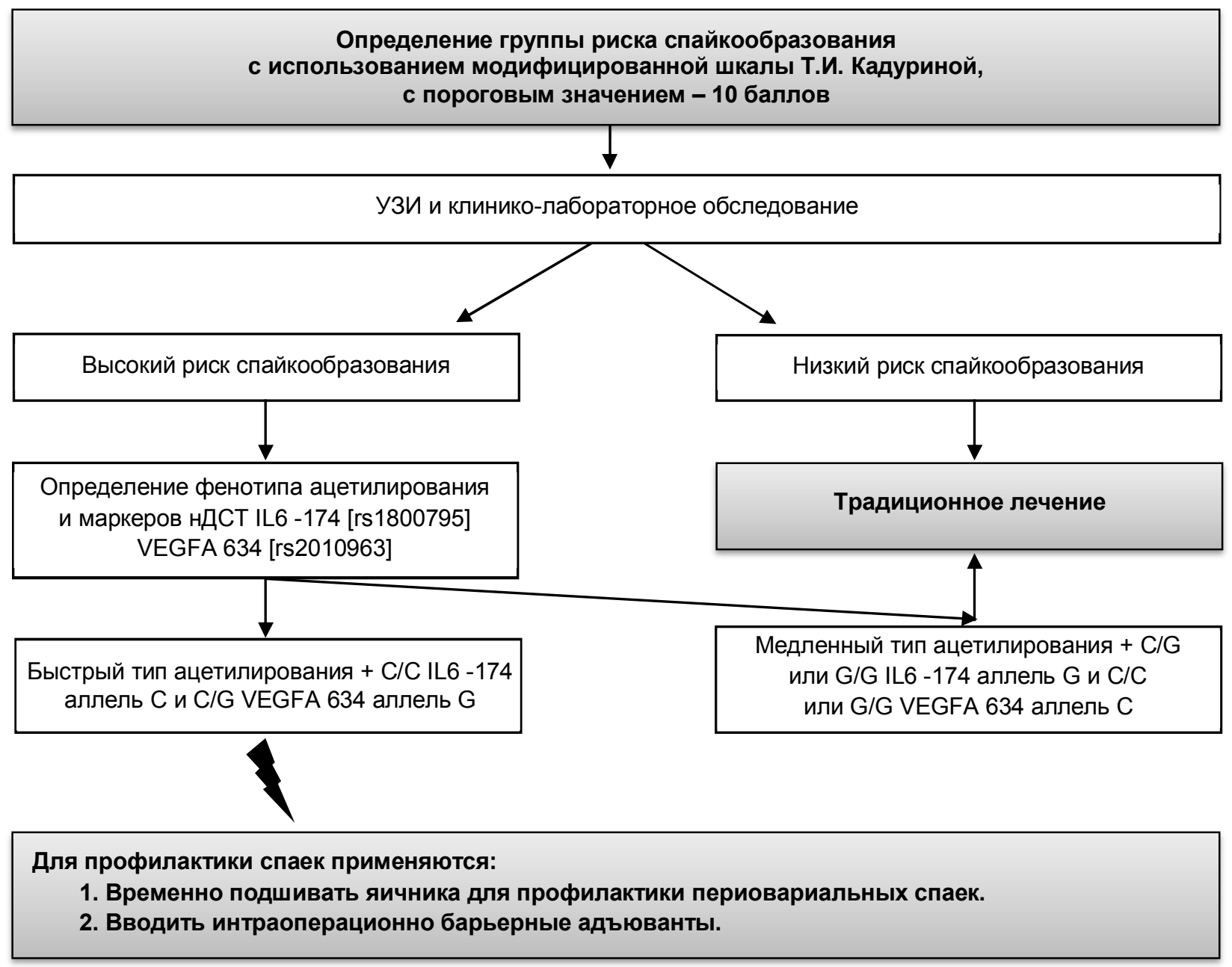

Рис. 9. Алгоритм ведения пациенток с ТПС на фоне нДСТ

На основании комплекса информативных, высокоточных и экономных методов аппаратной и лабораторной диагностики - профилирование фенотипических маркеров по модифицированной шкале Т.И. Кадуриной, фенотипирование ацетилирования и молекулярно-генетическое исследование полиморфизма генов (VEGF 634 [rs2010963] и IL6-174 [rs1800795]) - нами было проведено прогнозирование риска развития ТПС на фоне нДСТ.

Кроме того, нами была обоснована экономическая целесообразность выполнения комплексной методики: при высокой эффективности и безопасности для больных предложенная методика имеет экономические преимущества по сравнению с классической тактикой ведения пациентов группы риска.

При проведении комплексной методики экономические затраты не превышают следующих цифр:

- профилирование френотипических маркеров по модифицированной шкале Т.И. Кадуриной - 0 р.;
- фенотипирование ацетилирования колориметрическим методом - 300 р.;

- исследование полиморфизма генов VEGF 634 [rs2010963] и IL6-174 [rs1800795] - 3500 p.

Анализ экономических затрат показал, что на проведение комплексной методики потребуется около 3800 р. на человека, а операция адгезиолизиса требует затрат более 49 тыс. р. (по КСГ - 13, г. Рязань). Из чего можно сделать вывод о том, что высокая эфффективность предложенной нами комплексной методики имеет лапидарные экономические преимущества по сравнению с операцией адгезиолизиса, что, в свою очередь, дает основание говорить о целесообразности ее использования как в гинекологии, как и в других оперативных областях.

Таким образом, применение комплексной методики и противоспаечных барьеров дает возможность пациентке избежать хронической тазовой боли, повторных операций и психоэмоционального ущерба. 


\section{ЗАКЛЮЧЕНИЕ}

1. Клиническими признаками недифференцированной дисплазий соединительной ткани являются варикозное расширение вен нижних конечностей $(p=0,037)$, пролапс митрального клапана $(p=0,044)$, миопия $(p=0,0007)$ и хронический пиелонефрит ( $p=$ 0,024) а внешними фенотипическими - гиперпигментация кожи над остистыми отростками позвонков $(p<0,0001)$, наличие келоидных рубцов $(p<0,0001)$ и тонкой, легко ранимой кожи $(p<0,0001)$.

2. Диагностика генетической предрасположенности к спаечному процессу методом определения фенотипа ацетилирования позволяет предположить наличие спаек в малом тазу у 77,5 \% ( $p=0,033)$, а при применении ультразвуковой диагностики в 66,66 \% ( $p<0,0001)$ у обследованных пациенток до операции.

3. Предсказательная ценность УЗИ при диагностике СП на основании признаков: «нечеткий контур» является 49,18\% $(\mathrm{Cl}=0,57-1,55 ; \mathrm{OR}=0,94 ; p=$ $0,158)$, наличие жидкостных образований в малом тазу $-59,01 \%(\mathrm{Cl}=1,24-3,45 ; \mathrm{OR}=2,07 ; p<0,0001)$, «расстояние» - 72,13\% $(\mathrm{Cl}=3,83-11,73 ; \mathrm{OR}=6,70$; $p<0,0001)$ и фриксация яичника в абнормальной локализации - 79,5 \% (Cl = 8,08-28,03; OR = 15,05; $p<0,0001)$.

4. Специфичность ультразвукового исследования при диагностике спаечного процесса в малом тазу на основании косвенных критериев («нечеткий контур», «фиксация», «расстояние» и наличие жидкостных образований в малом тазу, не связанных с яичником) составляет при 3-4-й стадии распространения спаечного процесса - 97,05 \% (100-94,11\%), а при 1-2-й стадии - 43,48 \% (24-62,96 \%).

5. Признаками высокой вероятности развитии спаечного процесса при ГСГ являются «локуляции» и атипичное расположение маточной трубы.

6. При исследовании хронической тазовой боли в зависимости от стадии спаечного процесса было доказано и достоверно, что чем более продвинутая стадия спаечного процесса, тем более интенсивный характер хронической тазовой боли $(R=0,695$; $p<0,05$; критерий с2 = 67,25; коэфффициент взаимной сопряженности К. Пирсона 0,518).

7. Молекулярно-генетическими предикторами недифференцированной дисплазий соединительной ткани являются IL6-174 [rs1800795] генотип C/C ( $p=$ $0,039)$ и аллель C $(p=0,035)$ и VEGFA 634 [rs2010963] генотип $\mathrm{C} / \mathrm{G}(p=0,038)$ и аллель $\mathrm{G}(p=0,047)$.

8. Внедрение разработанного алгоритма прогнозирования риска развития тазовых перитонеальных спаек на фоне недифференцированной дисплазий соединительной ткани способствует сохранению репродуктивной функции (рис. 9).

\section{ЛИТЕРАТУРА}

1. Аюшинова Н.И., Шурыгина И.А., Шурыгин М.Г., Глинская Е.В. Оценка выраженности спаечного процесса в брюшной полости // Сибирский медицинский журнал (Иркутск). - 2014. - № 130 (7). - С. 10-14.
2. Барулин А.Е., Курушина О.В., Думцев В.В. Современные подходы к терапии хронической тазовой боли // РМЖ. - 2016. - № 13. - С. 847-851.

3. Гаспаров А.С., Дубинская Е.Д. Тазовые перитонеальные спайки: этиология, патогенез, диагностика, профилактика. - М.: ООО «Медицинское инфрормационное агентство», 2013. - $168 \mathrm{c.}$

4. Жидков С.А., Корик В.Е., Жидков А.С., Орсич Е.О. Оценка выраженности спаечного процесса // Молодой ученый. - 2016. - № 114 (10). - С. 483-486.

5. Жура А.В., Третьяк С.И., Хрыщанович В.Я., Макаревич Ж.А. Экспериментальная модель перитонеальных спаек // Экспериментальная хирургия. - 2017. - № 25 (4). C. 333-339. doi: 10.1484/2305-0047.2017.4.333.

6. Кадурина Т.И., Горбунова В.Н. Дисплазия соединительной ткани: руководство для врачей. - СПб.: ЭЛБИ, 2009. - 714 c.

7. Кан Н.Е., Тютюнник В.Л., Амирасланов Э.Ю., Балушкина А.А., Сухих Г.Т. Акушерские осложнения и недифференцированная дисплазия соединительной ткани // Клиническая и экспериментальная хирургия. 2015. - № 2. - С. 47-52.

8. Поройский С.В., Поройская А.В., Булычева О.С. Морфометрическая характеристика париетальной и висцеральной брюшины в динамике после нанесения операционной травмы различного объема // Вестник ВолгГМУ. - 2014. - 51 (3). - С. 102-107.

9. Степанюк А.А., Завада Н.В., Гуревич А.Р., Степанюк А.Ф. Современные подходы к диагностике и лечению спаечного процесса брюшной полости // Экстренная медицина. - 2014. - № 10 (2). - С. 55-64.

10. Филенко Б.П., Земляной В.П., Борсак И.И., Иванов А.С. Спаечная болезнь: профилактика и лечение. - СПб.: СЗГМУ им. И.И. Мечникова, 2013. - 171 с.

11. Чистяков Д.Б., Мовчан К.Н., Ященко А.С. Интенсивность фрормирования спаечного процесса при интраабдоминальном укреплении брюшной стенки в эксперименте синтетическими сетчатыми имплантами, отличающимися фиизио-химической основой строения // Вестник Северозападного государственного медицинского университета им. Мечникова. - 2015. - № 7 (3). - С. 29-37.

12. Broek R.P., Issa Y., van Santbrink E.J., Bouvy N.D., Kruitwagen R.F., Jeekel J., Bakkum E.A., Rovers M.M., van Goor $\mathrm{H}$. Burden of adhesions in abdominal and pelvic surgery: systematic review and metanalysis // BMJ. - 2013. № 3. - P. 347: f5588. doi: 10.1136/bmj.f5588.

13. De Mos M., Huygen F. Complex regional pain syndrome // Pain in women. - 2013. - № 335. - P. 229-245.

14. Kawanishi K., Yamato M., Sakiyama R. Peritoneal cell sheets composed of mesothelial cells and fibroblasts prevent intra-abdominal adhesion formation in a rat model // J. Tissue Eng. Regen. Med. - 2016. - № 10 (10). - P. 855866. doi: 10.1002/term. 1860.

15. Mosca M., Tani C., Vagnani S., Bombardieri S. The diagnosis and classification of undifferentiated connective tissue diseases // J. Autoimmun. - 2014. - № 48. P. $50-52$

16. Tabibian N., Swehli E., Boyd A., Umbreen A., Tabibian J.H. Abdominal adhesions: A practical review of an often overlooked entity // Ann. Med. Surg. (Lond). - 2017. № 31 (15). - P. 9-13. doi: 10.1016/j. amsu.2017.01.021

17. Saed G.M., Fletcher N.M., Diamond M.P. The Creation of a Model for Ex Vivo Development of Postoperative Adhesions // Reprod Sci. - 2016. - № 23 (5). - P. 610-612. doi: 10.1177/1933719115607997 


\section{REFERENCES}

1. Ayushinova N.I., SHurygina I.A., SHurygin M.G., Glinskaya E.V. Ocenka vyrazhennosti spaechnogo processa $\checkmark$ bryushnoj polosti [Assessment of the severity of adhesions in the abdominal cavity]. Sibirskij medicinskij zhurnal (Irkutsk) [Siberian Medical Journal (Irkutsk)], 2014, no. 130 (7), pp. 10-14. (In Russ.; abstr. in Engl.).

2. Barulin A.E., Kurushina O.V., Dumcev V.V. Sovremennye podhody $\mathrm{k}$ terapii hronicheskoj tazovoj boli [Modern approaches to the treatment of chronic pelvic pain]. RMZH [Russian Medical Journal], 2016, no. 13, pp. 847-851. (In Russ.; abstr. in Engl.).

3. Gasparov A.S., Dubinskaya E.D. Tazovye peritoneal'nye spajki: etiologiya, patogenez, diagnostika, profilaktika [Pelvic peritoneal adhesions: etiology, pathogenesis, diagnosis, prevention]. Moscow: OOO «Medicinskoe informacionnoe agentstvo», 2013. $168 \mathrm{p}$.

4. ZHidkov S.A., Korik V.E., ZHidkov A.S., Orsich E.O. Ocenka vyrazhennosti spaechnogo processa [Assessment of the severity of adhesions]. Molodoj uchenyj [Young scientist], 2016, no. 114 (10), pp. 483-486. (In Russ.; abstr. in Engl.).

5. ZHura A.V., Tret'yak S.I., Hryschanovich V.YA., Makarevich ZH.A. Eksperimental'naya model' peritoneal'nyh spaek [Experimental model of peritoneal adhesions]. Eksperimental'naya hirurgiya [Experimental Surgery], 2017, no. 25 (4), pp. 333-339. doi: 10.1484/2305-0047.2017.4.333. (In Russ.; abstr. in Engl.).

6. Kadurina T.I., Gorbunova V.N. Displaziya soedinitel'noj tkani: rukovodstvo dlya vrachej [Connective tissue dysplasia: a guide for physicians]. Saint Petersburg: ELBI, 2009. 714 p.

7. Kan N.E., Tyutyunnik V.L., Amiraslanov E.YU., Balushkina A.A., Suhih G.T. Akusherskie oslozhneniya i nedifferencirovannaya displaziya soedinitel'noj tkani [Obstetric complications and undifferentiated connective tissue dysplasia]. Klinicheskaya i eksperimental'naya hirurgiya [Clinical and experimental surgery], 2015, no. 2, pp. 47-52. (In Russ.; abstr. in Engl.).

8. Porojskij S.V., Porojskaya A.V., Bulycheva O.S. Morfometricheskaya harakteristika parietal'noj i visceral'noj bryushiny $\mathrm{v}$ dinamike posle naneseniya operacionno travmy razlichnogo ob"ema [Morphometric characteristics of the parietal and visceral peritoneum in the dynamics after the application of an operating injury of various sizes]. Vestnik VolgGMU [Journal of VolgSMU], 2014, 51 (3), pp. 102-107. (In Russ.; abstr. in Engl.).
9. Stepanyuk A.A., Zavada N.V., Gurevich A.R., Stepanyuk A.F. Sovremennye podhody k diagnostike i lecheniyu spaechnogo processa bryushnoj polosti [Modern approaches to the diagnosis and treatment of adhesions of the abdominal cavity]. Ekstrennaya medicina [Emergency medicine], 2014, no. 10 (2), pp. 55-64. (In Russ.; abstr. in Engl.).

10. Filenko B.P., Zemlyanoj V.P., Borsak I.I., Ivanov A.S. Spaechnaya bolezn': profilaktika i lechenie [Adhesive disease: prevention and treatment]. Saint Petersburg: SZGMU im. I.I. Mechnikova, 2013. 171 p.

11. CHistyakov D.B., Movchan K.N., YAschenko A.S. Intensivnost' formirovaniya spaechnogo processa pri intraabdominal'nom ukreplenii bryushnoj stenki v eksperimente sinteticheskimi setchatymi implantami, otlichayuschimisya fiziko-himicheskoj osnovoj stroeniya [The intensity of the formation of adhesions during intra-abdominal strengthening of the abdominal wall in the experiment synthetic mesh implants, differing physico-chemical basis of the structure]. Vestnik Severo-zapadnogo gosudarstvennogo medicinskogo universiteta im. Mechnikova [Herald of the North-Western State Medical University named after Mechnikov], 2015, no. 7 (3), pp. 29-37. (In Russ.; abstr. in Engl.).

12. Broek R.P., Issa Y., van Santbrink E.J., Bouvy N.D., Kruitwagen R.F., Jeekel J., Bakkum E.A., Rovers M.M., van Goor $\mathrm{H}$. Burden of adhesions in abdominal and pelvic surgery: systematic review and metanalysis. BMJ, 2013, no. 3, pp. 347: f5588. doi: 10.1136/bmj.f5588.

13. De Mos M., Huygen F. Complex regional pain syndrome. Pain in women, 2013, no. 335, pp. 229-245.

14. Kawanishi K., Yamato M., Sakiyama R. Peritoneal cell sheets composed of mesothelial cells and fibroblasts prevent intra-abdominal adhesion formation in a rat model. J Tissue Eng. Regen. Med, 2016, no. 10 (10), pp. 855-866. doi: 10.1002/term.1860.

15. Mosca M., Tani C., Vagnani S., Bombardieri S. The diagnosis and classification of undifferentiated connective tissue diseases. J. Autoimmun, 2014, no. 48, pp. 50-52.

16. Tabibian N., Swehli E., Boyd A., Umbreen A., Tabibian J.H. Abdominal adhesions: A practical review of an often overlooked entity. Ann. Med. Surg. (Lond), 2017, no. 31 (15), pp. 9-13. doi: 10.1016/j. amsu.2017.01.021

17. Saed G.M., Fletcher N.M., Diamond M.P. The Creation of a Model for Ex Vivo Development of Postoperative Adhesions. Reprod Sci, 2016, no. 23 (5), pp. 610-612. doi: $10.1177 / 1933719115607997$

\section{Контактная информация}

Бен Салха Мехди - аспирант кафедры акушерства и гинекологии ФГБОУ ВО РязГМУ им. акад. И.П. Павлова Минздрава РФ, e-mail: mr.bensalha@hotmail.fr 